\title{
AN EPIDEMIC OF WATER-BORNE DYSENTERY
}

\author{
GEORGE E. STOOKEY \\ Sanitary Corps, U. S. Army
}

On Aug. 28, 1918, it was brought to the writer's attention that diarrhea of a very violent type was attacking the inhabitants of Bertrichamp, a town of about 2,000 population, in the department of Meurthe-Moselle, France.

Investigation brought out the following facts: 1 . The symptoms of the disease were practically identical in all cases where it was possible to obtain information. Enteric pains were soon followed by diarrhea. Stools were frequent and contained large quantities of blood and mucus which persisted in the feces from two to eight days in the various cases. Passages were accompanied by considerable tenesmus. No vomiting was reported. A rise in temperature to from 99.5 to $100.5 \mathrm{~F}$. was noted in all cases, as well as marked increase in the pulse rates. Several patients seemed apparently on the way to recovery when a sudden collapse, followed by fatal termination of the disease, occurred. 2. Lack of ventilation, and large numbers of flies were noted in all rooms where patients were found. 3. Persons attacked varied in age between 5 and 69 years. 4. No patient had drunk milk or eaten uncooked vegetables for some time prior to the onset of the disease. 5. All patients but two admitted having drunk water from the public supply a short time, usually two or three days, before the first attack. The two who did not admit having drunk water were young children whose evidence was not entirely trustworthy.

The usual precautions were immediately taken to prevent further spread of the disease. Feces were sterilized and buried, flies were driven out, ventilation and cleanliness insisted on. On August 29 the order was given to boil all water used.

Possibly it may not here be out of place to note that a Frenchman will admit drinking water only very reluctantly. For epidemiologic purposes this has a double meaning: Any water history, although more difficult to obtain, will be very accurate; more important, perhaps, any water-borne epidemic will be less widespread in a French town of given population than in an American town having an equal number of inhabitants. 
Cases appeared on the following days:

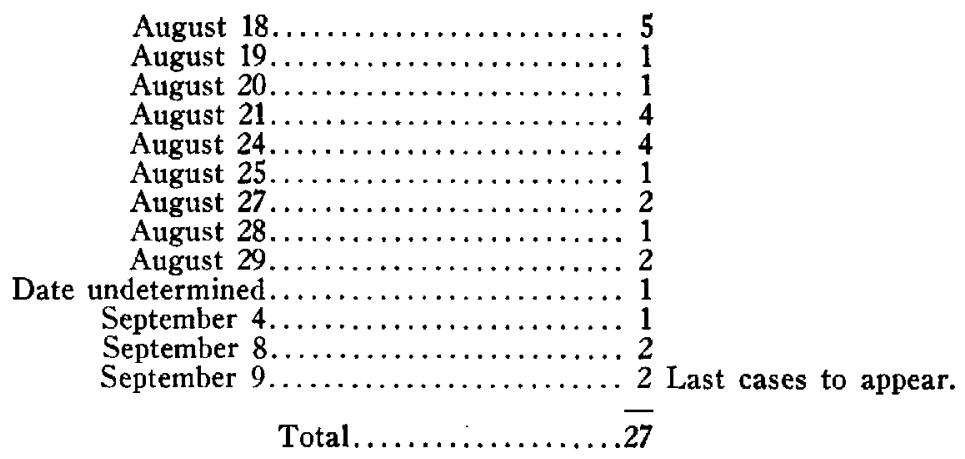

Among the cases, 7 appeared in families which had a previous case of the disease. Of the 7, five appeared after August 24, so may be regarded as possible contact developments.

Of the cases which developed during September, two had visited friends sick of the disease, and two had ignored the order to boil water before using. The patient who developed diarrhea September 4 had used only boiled water since August 29 and had visited no one.

Cultures from feces of patients showed a nonmotile, gram-negative bacterium having the morphology of $B$. dysenteriae, which gave the growth and reddening characteristic of $\mathrm{B}$. dysenteriae and $\mathrm{B}$. typhosus on Russell's double sugar medium, and which failed to agglutinate with an antityphoid serum of known potency; because of complicating factors, it was not possible to make direct agglutination tests for $B$. dysenteriae.

Treatment given patients by the civilian doctor in attendance consisted in an almost total restriction of diet, three or four tablespoonfuls of sugar-water being given during the day. In only two cases was antidysentery serum given - both times after the disease had been running several days - and then only in very limited amounts.

Deaths among civilian patients occurred on the following days:

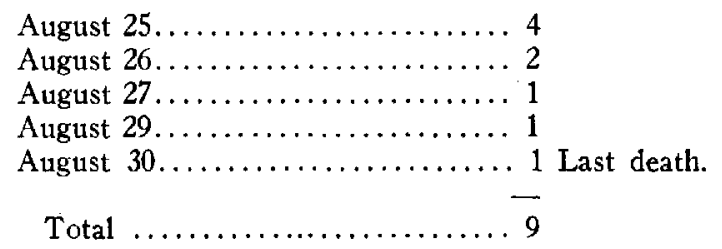

The death rate, as will be noted, was 33 per-cent. The probable reasons for this high mortality lie in the poor physical conditions of 
the patients, consequent on four years of poor nutrition and bad living conditions; and in the insufficient treatment given those sick of the disease.

During the period from August 20 to August 30 one French and six American soldiers suffering from diarrhea of the same type were admitted to the military hospitals of this area. Investigation showed that these men had all been quartered in Bertrichamp. Each gave a history of having drunk untreated water from fountains on the main source of supply for the town from two to four days before coming to the hospitals. Cultures from feces were made and B. dysenteriae Flexner found in five of the cases.

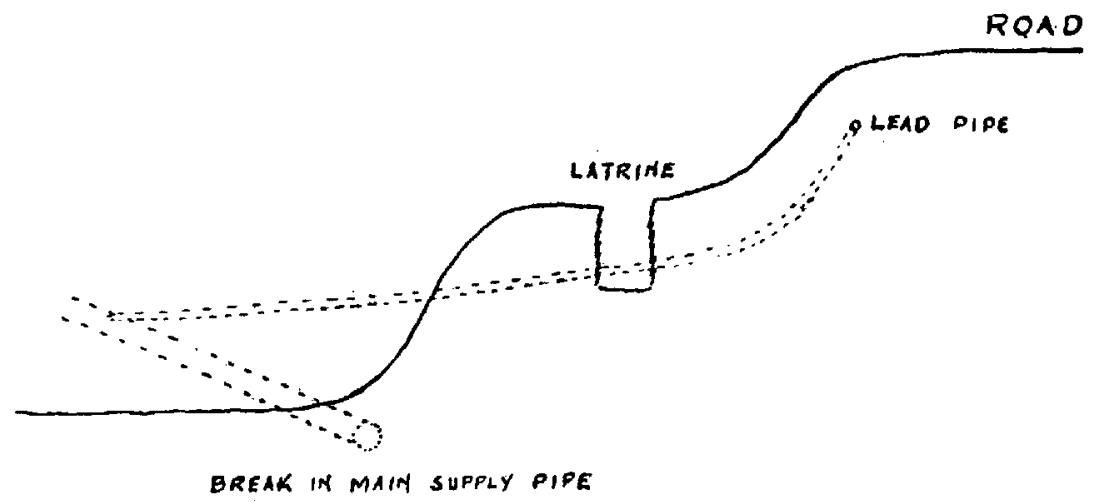

Fig. 1.-Break in main supply pipe from which water flowed saturating soil about latrine and causing contamination of drinking water.

Among the soldiers the disease was not so severe as among the civilians. Recoveries were more rapid and there were no deaths. The better nourishment and treatment is doubtless responsible for this condition:

The water supply of Bertrichamp is of the low-pressure, continousflowing-fountain type frequently found in the villages of the Vosges mountains. There are four separate sources from which water is brought into the town by terra-cotta mains. Each of these distribution systems supplies fountains in a different section of the town and is in no way connected with the other sources. The main supply (on which are 10 of the 16 fountains of the town) comes from springs in the forest about two miles back of the town.

A bacteriologic examination of water from each of the fountains of the town was made on August 28. These examinations showed that three of the sources of supply were excellent, but that on the main 
source of supply for the town all of the fountains save one gave water which was badly contaminated. This fountain, from which the water was excellent, was the first on the pipe coming from the springs, or the one nearest the source of supply, higher than and perhaps a quarter of a mile from the next fountain on this same pipe line. Samples from the springs showed the water to be uniformly excellent. Samples taken on the two succeeding days confirmed the first analyses. Fountains designated by the patients as those from which they had drunk were all on the supply line from which the water was contaminated.

These analyses indicated a point of contamination between the first and second fountains on the main supply line. Search revealed a break in one joint of the pipe. This joint was directly behind, 15 feet from and 12 feet lower than a latrine dug into the downward sloping bank at the edge of the road. The latrine had been used for three months by passing troops, and had been filled with earth on August 27. A lead pipe which supplied the second fountain on this line was set into the main supply line about 30 feet above the break and ran diagonally up the bank, passing directly behind the latrine and under the road. Steps leading to the latrine exposed this pipe at a point about 6 feet beyond and 2 feet higher than the top of the latrine. Here the lead pipe had been cut and was flowing about 3 gallons per minute, thus causing the earth around the latrine and between it and the main pipe to be thoroughly saturated with water. Fecal matter, practically fresh and undecomposed, was found in veins running about and over the main supply pipe. The main supply pipe was repaired and the condition finally corrected on September 6.

Military reasons made it necessary for the writer to leave this section about a week later. At the time of departure all of the patients had recovered or were doing well. Reports from the secretary of the town showed that no new cases developed later in September or during October, nor were there any further deaths.

\section{CONCLUSIONS}

The causative factor of the epidemic reported was B. dysenteriae of the Flexner type.

The principal carrier of infection in the above epidemic was water from the main source of supply for the town of Bertrichamp. 